\title{
The problem of predicting food intake during the period of adaptation to a new food: a model
}

\author{
Emma C. Whittemore*, Gerry C. Emmans and Ilias Kyriazakis \\ Animal Nutrition and Health Department, Animal Biology Division, \\ Scottish Agricultural College, West Mains Road, Edinburgh EH9 3JG, UK
}

(Received 10 December 2001 - Revised 10 September 2002 - Accepted 3 October 2002)

\begin{abstract}
A model is described which aims to predict intake immediately following a change from one food to another that is higher in bulk content; it deals with the transition from one 'equilibrium' intake to another. The system considered is an immature pig fed ad libitum on a single homogeneous food, which is balanced for nutrients and contains no toxins so that the first limiting resource is always energy. It is assumed that an animal has a desired rate of food intake (DFI) which is that needed to meet the energy requirements for protein and lipid deposition and for maintenance. DFI may not be achieved if a bulk constraint to intake exists. Where a bulk constraint operates intake is calculated as constrained food intake $(\mathrm{CFI})$ where $\mathrm{CFI}=$ $\mathrm{C}_{\text {whc }} / \mathrm{WHC} \mathrm{kg} / \mathrm{d}$ (where WHC is the water-holding capacity of the food ( $\mathrm{kg}$ water $/ \mathrm{kg}$ dry food) and $\mathrm{C}_{\mathrm{whc}}$ is the animal's capacity for WHC (units/kg live weight per d)). Where intake is not constrained it is assumed that genetic potential will be achieved. Potential growth rate is described by the Gompertz growth function. Where intake is constrained, growth will be less than the potential. Constrained growth rate is predicted as $(\mathrm{dW} / \mathrm{dt})_{\mathrm{con}}=(\mathrm{EI}-$ $\left.E_{m}\right) / e_{g} \mathrm{~kg} / \mathrm{d}$ where $\mathrm{W}$ is pig weight $(\mathrm{kg})$, EI is energy intake $(\mathrm{MJ} / \mathrm{d}), \mathrm{E}_{\mathrm{m}}$ is the energy required for maintenance $(\mathrm{MJ} / \mathrm{d})$ and $\mathrm{e}_{\mathrm{g}}$ is the energy required for unit gain $(\mathrm{MJ} / \mathrm{kg})$. The value of $\mathrm{e}_{\mathrm{g}}$ depends on weight and the fattening characteristics of the pig. Actual growth is predicted to be the lesser of potential and constrained growth. To deal with adaptation it is assumed that the time taken to reach equilibrium depends on the difference in WHC values between the previous and current food and that the capacity to consume food bulk is related to the WHC of the current food. It is proposed that the capacity for WHC on the first day on a new food will be equal to the current capacity for WHC on the last day of the previous food. Thus $\mathrm{C}_{\mathrm{whc}}=(\mathrm{FI} \times$ $\mathrm{WHC}) / \mathrm{Wg} / \mathrm{kg}$, where FI is food intake $(\mathrm{kg} / \mathrm{d})$. Thereafter $\mathrm{C}_{\mathrm{whc}}$ will gradually increase over time to a maximum of $0.27 \mathrm{~g} / \mathrm{kg}$. The rate of change in $\mathrm{C}_{\mathrm{whc}}$ is made to be the same for all pigs and all foods. The increase in capacity over time is assumed to be linear at the rate of 0.01 units/d. The model was tested using published data. Qualitatively the predictions of the model were in close agreement with the relevant observed data in at least some cases. It is concluded that the underlying theoretical assumptions of the model are reasonable. However, the model fails to predict initial intake when changed to foods high in wheat-bran content and fails to predict the intake of a non-limiting food where compensatory increases in intake and gain occur. The model could be adapted to overcome the first failure by taking into account the time course of digestive efficiency following a change in food. To deal with the second would require a sufficient understanding of the time course of compensatory growth.
\end{abstract}

Adaptation: Food intake: Fibre: Pigs: Water-holding capacity

Some current models of food intake seek to predict the way in which the intake of a given food will change over time (Black et al. 1986; Ferguson et al. 1994; Kyriazakis \& Emmans, 1995, 1999; Emmans, 1997; Giles et al. 1998;
Whittemore et al. 2001a). These models assume that the animal is always fully adapted to the food it is on, i.e. equilibrium with the food is presumed. This approach, however, does not account for the immediate effects of a

\footnotetext{
Abbreviations: ASH, ash content; CFI, constrained food intake; CP, crude protein; DE, dietary energy; DFI, desired food energy intake; EE, effective energy; EI, energy intake; FEEC, energy content of food; FI, food intake; L, lipid weight; LPR $\mathrm{m}_{\mathrm{m}}$ lipid:protein at maturity; ME, metabolisable energy; P, protein weight; RQ, requirement for energy; SBP, sugar-beet pulp; W, (current) body weight; WA, water; WAPR ${ }_{\mathrm{m}}$, protein:water at maturity; WB, wheat bran; WHC, water-holding capacity.

* Corresponding author: Dr E. C. Whittemore, fax +44 131333 3296, email ewhittemore@ aviagen.com
} 
change in food type upon intake. A change in food type may have important consequences for both food intake and performance, particularly when the change is from one food to another of poorer nutritional quality (for example, Kyriazakis \& Emmans, 1995; Whittemore et al. 2001c). Changing to a food with a greater bulk content results, initially, in a reduction in food intake and performance (Kyriazakis \& Emmans, 1995; Tsaras et al. 1998; Whittemore et al. 2001c).

The reduction in food intake is a reflection of the fact that the gastrointestinal tract is not adapted to the new food. It is the result of the physical 'bulk' of the new food exceeding the capacity of the gastrointestinal tract for bulk (Cole et al. 1972; Kyriazakis \& Emmans, 1995). After the initial reduction in intake there is a transition period during which intake gradually increases until the new equilibrium intake is reached. This is determined by the 'bulk' content of the food and the capacity of the gastrointestinal tract for bulk (Kyriazakis \& Emmans, 1995; Tsaras et al. 1998). Adaptation involves accommodation of the gastrointestinal tract to the increased gut fill or to the increased involvement of parts of the gut in fibre digestion (Kyriazakis \& Emmans, 1995). The increase in intake over time, during this period of adaptation, is the result of an increase in the weight (size) and volume of the gastrointestinal tract, particularly of the large intestine (Low, 1985; Kyriazakis \& Emmans, 1995).

The length of the adaptation period, and the extent to which food intake is initially reduced after a change in food type, have both been shown to be related to the difference in bulk content between the two foods (Kyriazakis \& Emmans, 1995; Tsaras et al. 1998; Whittemore et al. 2001c). Previous nutritional history will have significant effects on adaptation. For example, animals that have had previous experience of bulky foods show an enhanced capacity for bulk. Whittemore et al. (2001c) found that pigs with previous experience of bulky foods were able to consume up to 1.4 times as much of a high-bulk food than pigs that had previously been fed a low-bulk food. Kyriazakis \& Emmans (1995) showed that previous experience of bulky foods led to a reduction in the time taken to adapt to a bulky food and to an increase in food intake.

The adaptation period has important implications for the intake and performance of pigs fed high bulk foods. It is during this time that food intake and performance will be depressed to the greatest extent and it may take up to $14 \mathrm{~d}$ for an animal to become fully adapted to a new food which is high in bulk (Kyriazakis \& Emmans, 1995). The ability to predict the extent to which intake and performance will be depressed, and for how long the period of adaptation will last after a change in food type, will allow more accurate food intake prediction models for high-bulk foods to be developed, and may help to develop feeding strategies that will minimise the effects of adaptation. Despite this, data recorded during the period of adaptation are frequently excluded in order to make the prediction of food intake on high-bulk foods easier (for example, Kyriazakis \& Emmans, 1995; Tsaras et al. 1998). The aim of the present work is to develop a model that will predict intake and performance during the transition period between equilibrium intakes when the animal is changed from one food type to another of a different bulk content. The approach is expected to complement existing models that predict the food intake of pigs. Previous work (Kyriazakis \& Emmans, 1995; Tsaras et al. 1998) has shown that 'bulk' as a limit to food intake can be measured by the capacity of the food to hold water; the water-holding capacity (WHC). This was the case across a very wide range of foods differing in digestibility and fibre content assessed in different ways. Consequently WHC is used as the measure of food bulk in the model described here.

Changes made to food composition in practice are likely to be much smaller than those considered here. However, it is by considering the effects of larger changes that those of smaller ones can be better understood. In experiments where the aim is to measure equilibrium intakes the time needed to do this following a change of food is relevant.

\section{Materials and methods \\ Description of the model}

General. The system being considered is an immature pig fed ad libitum on a single, homogeneous food that is balanced for nutrients and contains no toxins, so that the first limiting resource is always energy. The environment is always maintained at thermoneutrality. For the purposes of the model, it is assumed that the pig eats to attain its genetic potential for performance subject only to the presence of constraints (Black et al. 1986; Emmans, 1988, 1997; Ferguson et al. 1994; Poppi et al. 1994; Kyriazakis \& Emmans, 1999). According to this framework animals are assumed to have a desired food energy intake (DFI) which is determined by the genetic potential for protein deposition, the desired rate of lipid deposition, and by the current requirement for maintenance (Kyriazakis \& Emmans, 1999). In a thermally neutral environment, it is only these 'goals' that determine the rate of food intake needed to meet the requirement for energy. It is possible that constraints arising from the food being offered may prevent DFI from being met. The only constraint to food intake considered here is the bulk content of the food. Where a bulk constraint operates, actual food intake is predicted to be less than DFI and hence genetic potential is not achieved. The prediction of DFI, with all of its attendant difficulties (Whittemore et al. 2001a), is thus a necessary first step in the prediction of actual intake in a given case. Where a bulk constraint operates, actual food intake is calculated as constrained food intake (CFI). CFI is a function of the bulk content of the food and the capacity of the pig to deal with that bulk (Kyriazakis \& Emmans, 1995, 1999; Tsaras et al. 1998). The bulk content of a food is measured by its WHC, which is a measure of material's ability to hold water within its matrix and has been shown to be a good indicator of food bulk (Kyriazakis \& Emmans, 1995; Tsaras et al. 1998).

The theoretical assumptions laid out above form the basis of the model, the aim of which is to predict food intake and performance during the transitory period when a change in food type from one food to another of a higher bulk content occurs. There were several stages 
of model development. The first step was to predict equilibrium food intake as a function of the animal's current state. Next the model was made dynamic, so that changes in equilibrium intake and performance over time could be predicted. For this purpose, the rate of change of state as weight gain was made a function of genotype, current state and predicted intake (Emmans, 1997). The third stage was to make the model able to deal with the transitory period when a change in food type from one food to another of higher bulk content occurs. It was assumed that the time taken to reach equilibrium depends on the difference in WHC between the foods. The capacity to consume food bulk is assumed to be related to the WHC of the current food (Kyriazakis \& Emmans, 1995).

\section{Static model}

Potential growth. Where food intake is not constrained it is assumed that genetic potential, or maximal growth, can be achieved. For immature animals potential growth can be described by the Gompertz growth function (Emmans, 1988; Emmans \& Kyriazakis, 1999, 2001). This approach has been successfully used for pigs by Whittemore et al. (1988) and more recently by Knap (2000). Potential growth rate at a given weight is given by:

$$
(\mathrm{dW} / \mathrm{dt})_{\max }=\mathrm{B} \times \mathrm{W} \times \log _{\mathrm{e}}(\mathrm{A} / \mathrm{W}) \mathrm{kg} / \mathrm{d},
$$

where $\mathrm{W}$ is current body weight $(\mathrm{kg}), \mathrm{B}$ is a rate parameter (/d) and $\mathrm{A}$ is mature size $(\mathrm{kg})$.

Energy requirement. Energy is the only resource that will be considered. The scale of energy used to estimate requirements is important and here the effective energy (EE) scale developed by Emmans (1994) is used. The advantages of this system have been discussed elsewhere (Emmans, 1994; 1997; Emmans \& Kyriazakis, 2001). In principle, however, any other energy system (for example, Agricultural Research Council, 1981; National Research Council, 1987; Noblet et al. 1993) could be used in its place. The starting point for the EE system is metabolisable energy (ME), which is corrected for the digestibility and fermentability of the diet and for its protein and lipid contents. It is assumed that the EE requirements for unit gains of protein and lipid are constant across foods and level of feeding. These requirements were also found to be constant across species and degrees of maturity (Emmans, 1994).

The requirement for $\mathrm{EE}\left(\mathrm{EE}_{\mathrm{rq}}\right)$ by the growing animal is calculated as the sum of the requirements for maintenance $(\mathrm{m})$, protein retention (pr) and lipid retention (lr) as follows:

$$
\mathrm{EE}_{\mathrm{rq}}=\mathrm{EE}_{\mathrm{m}}+\mathrm{EE}_{\mathrm{rqgain}} \mathrm{MJ} / \mathrm{d} \text {, }
$$

where $\mathrm{EE}_{\mathrm{m}}(\mathrm{MJ} / \mathrm{d})$ is the $\mathrm{EE}$ required for maintenance, $\mathrm{EE}_{\mathrm{rqgain}}(\mathrm{MJ} / \mathrm{d})$ is the $\mathrm{EE}$ required for potential protein and lipid growth at a given weight (see Energy required for gain; p. 385).

The EE required for maintenance is assumed to be directly proportional to weight (W) and can be calculated as:

$$
\mathrm{E}_{\mathrm{m}}=a \times \mathrm{WMJ} / \mathrm{d} \text {. }
$$

Although there are good reasons for assuming that maintenance is directly related to protein weight rather than body weight (Emmans, 1987, 1994), for the purposes of the current model the use of body weight to predict the requirements for maintenance is considered to be adequate. The aim of this part of the model is not to predict whole pig growth but rather to provide a basis from which a model to predict intake and performance during the adaptation period to bulky foods could be developed. In addition to this, body protein content is not expected to change much over the weight range of interest and hence little extra accuracy will be gained by using protein weight rather than weight.

Predicting food intake. Where food intake is unconstrained and maximum performance can be achieved, an animal is presumed to eat at a level that will allow its requirements to be met so that:

$$
\mathrm{DFI}=\mathrm{RQ} / \mathrm{FEEC} \mathrm{kg} / \mathrm{d} \text {, }
$$

where RQ $(\mathrm{MJ} / \mathrm{d})$ is the requirement for energy and FEEC is the energy content of the food $(\mathrm{MJ} / \mathrm{kg})$. As long as RQ can be predicted, and FEEC is known or can be calculated, then DFI can be predicted.

Where intake is constrained by the bulk content of the food it will be determined by the animal's capacity for bulk and the bulk content of the food so that a constrained food intake $(\mathrm{CFI})$ is given by:

$$
\mathrm{CFI}=\mathrm{C}_{\mathrm{whc}} / \mathrm{WHC} \mathrm{kg} / \mathrm{d},
$$

where $\mathrm{C}_{\mathrm{whc}}(\mathrm{kg} \mathrm{WHC} / \mathrm{kg}$ live weight per $\mathrm{d})$ is the animal's maximum capacity for water-holding capacity and WHC ( $\mathrm{kg}$ water $/ \mathrm{kg}$ dry food) is the water-holding capacity of the food. Kyriazakis \& Emmans (1995) and Tsaras et al. (1998) found that, over the weight range $12-45 \mathrm{~kg}$ in pigs, the capacity for bulk was directly proportional to the animal's weight $(\mathrm{W})$, so that:

$$
\mathrm{C}_{\mathrm{whc}}=x \times \mathrm{W} \text { units } / \mathrm{d} \text {. }
$$

The value of $x$ is defined later (p. 387). Actual food intake (FI) is then predicted as the lower of DFI and CFI.

Actual energy intake (EI, MJ/d) which is used to calculate growth on a constraining food (see below) is then calculated as follows:

$$
\mathrm{EI}=\mathrm{FI} \times \mathrm{FEEC} \mathrm{MJ} / \mathrm{d} .
$$

Pig growth on a constraining food. On a food where intake is constrained, growth rate will be less than the potential. Weight gain on a constraining food is predicted from the following energy relationship:

$$
(\mathrm{dW} / \mathrm{dt})_{\mathrm{con}}=\left(\mathrm{EI}-\mathrm{E}_{\mathrm{m}}\right) / \mathrm{e}_{\mathrm{g}} \mathrm{kg} / \mathrm{d},
$$

where $E_{m}(\mathrm{MJ} / \mathrm{d})$ is the energy required for maintenance and $e_{g}(\mathrm{MJ} / \mathrm{kg})$ is the energy required for unit growth. All energy values are expressed as EE (Emmans, 1994).

Actual growth is then predicted to be the lesser of potential $\left((\mathrm{dW} / \mathrm{dt})_{\max }\right)$ and constrained $\left((\mathrm{dW} / \mathrm{dt})_{\text {con }}\right)$ growth.

Energy required for gain. For the model to work the energy required for potential growth, $\mathrm{EE}_{\mathrm{rqgain}} \mathrm{MJ} / \mathrm{d}$, and the energy needed per unit of constrained growth, $e_{g} \mathrm{MJ} /$ $\mathrm{kg}$, for constrained growth need to be calculated. It is assumed that energy is needed above maintenance only for protein and lipid retention and that the composition 
of the gain of a given kind of pig is constant regardless of the type of food being fed. These rates of retention need to be estimated as functions of $\mathrm{W}$, as this is the variable used in the model to describe pig size. A separate body composition sub-model was used to achieve this.

The sub-model was set up as a spreadsheet to predict $\mathrm{W}$, protein weight $(\mathrm{P})$, and lipid weight $(\mathrm{L})$, from birth, at $\mathrm{W}=$ $1.0 \mathrm{~kg}$, to maturity for different kinds of pig. All pigs were assumed to have the same mature protein mass $\left(\mathrm{P}_{\mathrm{m}}\right)$ of $40 \mathrm{~kg}$ but to have different lipid:protein at maturity $\left(\mathrm{L}_{\mathrm{m}}: \mathrm{P}_{\mathrm{m}} ; \mathrm{LPR}_{\mathrm{m}}\right)$. Values of $\mathrm{P}$ between $0.1 \mathrm{~kg}$ and $\mathrm{P}_{\mathrm{m}}$ were set as a column in the spreadsheet. The weights of the other chemical components of the body were then calculated assuming allometric relationships (Emmans \& Fisher, 1986; Emmans \& Kyriazakis, 1995). For ash content (ASH), water (WA) and L the relationships used (Emmans \& Kyriazakis, 1997) were:

$$
\begin{gathered}
\mathrm{ASH}=k_{1} \times \mathrm{P}^{b} \mathrm{~kg}, \\
\mathrm{WA}=k_{2} \times \mathrm{P}^{c} \mathrm{~kg}, \\
\mathrm{~L}=k_{3} \times \mathrm{P}^{d} \mathrm{~kg} .
\end{gathered}
$$

Body weight is then calculated as the sum of $\mathrm{P}, \mathrm{WA}, \mathrm{ASH}$ and $\mathrm{L}$. The values of the parameters for ash and the parameter $c$ for water were assumed to be constant across pigs. The values of the water parameter $k_{2}$ was made a function of the mature protein:water at maturity $\left(\mathrm{WAPR}_{\mathrm{m}}\right)$ and the lipid parameters, $k_{3}$ and $d$, were made functions of $\mathrm{LPR}_{\mathrm{m}}$ as described in Estimation of the body composition parameters (p. 386).

Different forms were used to describe the relationships between $\mathrm{P}$ and $\mathrm{W}$, and $\mathrm{L}$ and $\mathrm{W}$ for each of a range of $\mathrm{LPR}_{\mathrm{m}}$ values of $0.5,1.0 \ldots 5 \cdot 0$. The first form used was that of the simple allometric: $\mathrm{P}=\mathrm{x}_{1} \times \mathrm{W}^{\mathrm{y}}$ and $\mathrm{L}=$ $\mathrm{x}_{2} \times \mathrm{W}^{\mathrm{z}}$ following Whittemore et al. (1988). This form of function was rightly criticised by Schinckel (1999) and its use here resulted in large systematic deviations between the values predicted by the function and the input data. Schinkel (1999) suggested that an augmented allometric function of the form $\mathrm{Y}=a \mathrm{X}^{\mathrm{b}}(\mathrm{c}-\mathrm{X})^{\mathrm{d}}$ would be better at describing the relationships between $\mathrm{P}$ and $\mathrm{W}$ and $\mathrm{L}$ and $\mathrm{W}$. However, there is no theoretical reason for using this form rather than other simpler functional forms such as the quadratic. The form of the augmented allometric function will not, therefore, be considered further. A simple linear function described the relationships between $\mathrm{P}$ and $\mathrm{W}$, and $\mathrm{L}$ and $\mathrm{W}$ better than the simple power function but gave deviations that were systematic and larger than were judged to be satisfactory. Deviations from a quadratic model were also systematic, but were acceptably small for the present purpose as illustrated in Fig. 1(a) for protein and Fig. 1(b) for lipid. The relationships between $\mathrm{P}$ and $\mathrm{W}$ and $\mathrm{L}$ and $\mathrm{W}$ were thus estimated from:

$$
\begin{aligned}
& \mathrm{P}=a_{1}+\left(b_{1} \times \mathrm{W}\right)+\left(c_{1} \times \mathrm{W}^{2}\right) \mathrm{kg}, \\
& \mathrm{L}=a_{2}+\left(b_{2} \times \mathrm{W}\right)+\left(c_{2} \times \mathrm{W}^{2}\right) \mathrm{kg} .
\end{aligned}
$$

From the above equations, the protein and lipid contents of live-weight gain at a live weight become:

$$
\begin{aligned}
& \mathrm{dP} / \mathrm{dW}=b_{1}+\left(2 c_{1} \times \mathrm{W}\right) \mathrm{kg} / \mathrm{kg}, \\
& \mathrm{dL} / \mathrm{dW}=b_{2}+\left(2 c_{2} \times \mathrm{W}\right) \mathrm{kg} / \mathrm{kg} .
\end{aligned}
$$

The values of the four parameters, $b_{1}, c_{1}, b_{2}$, and $c_{2}$ were estimated for a type of pig with a particular value of $\mathrm{LPR}_{\mathrm{m}}$.

The value of $\mathrm{e}_{\mathrm{g}}$ can now be estimated as:

$$
\mathrm{e}_{\mathrm{g}}=\left(z_{1} \times \mathrm{dP} / \mathrm{dW}\right)+\left(z_{2} \times \mathrm{dL} / \mathrm{dW}\right) \mathrm{MJ} / \mathrm{kg} .
$$

The constants $z_{1}$ and $z_{2}$ are the amounts of energy (MJ) required for the deposition of $1 \mathrm{~kg}$ of protein and lipid respectively (see Table 1). The total energy required for gain, $\mathrm{EE}_{\mathrm{rqgain}}(\mathrm{MJ} / \mathrm{d})$ is calculated as:

$$
\mathrm{EE}_{\mathrm{rqgain}}=(\mathrm{dW} / \mathrm{dt})_{\max } \times \mathrm{e}_{\mathrm{g}} \mathrm{MJ} / \mathrm{d} \text {. }
$$

It is assumed that the composition of the gain for a particular kind of pig is always the same at a given live weight on a balanced food, irrespective of intake.

Estimation of the body composition parameters. The parameters, $b$ and $k_{1}$ in equation (9), for determining the ash content of the gain in the body composition submodel, are taken from Emmans \& Kyriazakis (1997). With the value of $b=1$ the parameter $k_{1}$ is the ash:protein at all values of $P$; it is assumed to be $0 \cdot 20$. The value of the water exponent $c$ in equation (10) is also assumed to be constant across genotypes and food (Emmans \& Kyriazakis, 1995) and to have the value of 0.855 (Kotarbinska, 1969). The value of the water scalar $k_{2}$ in equation (10) is calculated on the assumption that the $\mathrm{WAPR}_{\mathrm{m}}$ is the same for all pigs and is not correlated with mature protein weight (Emmans \& Kyriazakis, 1995). The value of $k_{2}$ is then estimated from:

$$
k_{2}=\mathrm{WAPR}_{\mathrm{m}} \times \mathrm{P}_{\mathrm{m}}^{1-c},
$$

where WAPR $\mathrm{W}_{\mathrm{m}}$ is 3.04 (Emmans \& Kyriazakis, 1995) and $c=0 \cdot 855$. The value of $k_{2}$ is actually constant because $\mathrm{P}_{\mathrm{m}}$ is assumed to have a constant value of $40 \mathrm{~kg}$.

The value of the lipid exponent $d$ in equation (11) depends on $\mathrm{LPR}_{\mathrm{m}}$. Emmans (1997) found that the value of $d$ could be estimated from:

$$
d=1.46 \times \mathrm{LPR}_{\mathrm{m}}^{0.23} .
$$

The value of $k_{3}$ in equation (11) is calculated as:

$$
k_{3}=\mathrm{LPR}_{\mathrm{m}} \times \mathrm{P}_{\mathrm{m}}^{1-d} \text {. }
$$

The 'data' generated by the body composition submodel in the spreadsheet were used to estimate the values $b_{1}$ and $c_{1}$ for protein, and $b_{2}$ and $c_{2}$ for lipid in the quadratic relationships between $\mathrm{P}$ and $\mathrm{W}$ and $\mathrm{L}$ and $\mathrm{W}$ for $\mathrm{LPR}_{\mathrm{m}}$ values of $0.5,1.0,1.5 \ldots 5.0$ in turn. The values of each of $b_{1}, c_{1}, b_{2}$ and $c_{2}$ were then made quadratic functions of $\mathrm{LPR}_{\mathrm{m}}$ so that:

$$
b_{1}=g_{1}+\left(h_{1} \times \mathrm{LPR}_{\mathrm{m}}\right)+\left(j_{1} \times \mathrm{LPR}_{\mathrm{m}}^{2}\right),
$$

with analogous equations for the other three parameters. The values of $g, h$ and $j$ for each of $b_{1}, c_{1}, b_{2}$ and $c_{2}$ are 


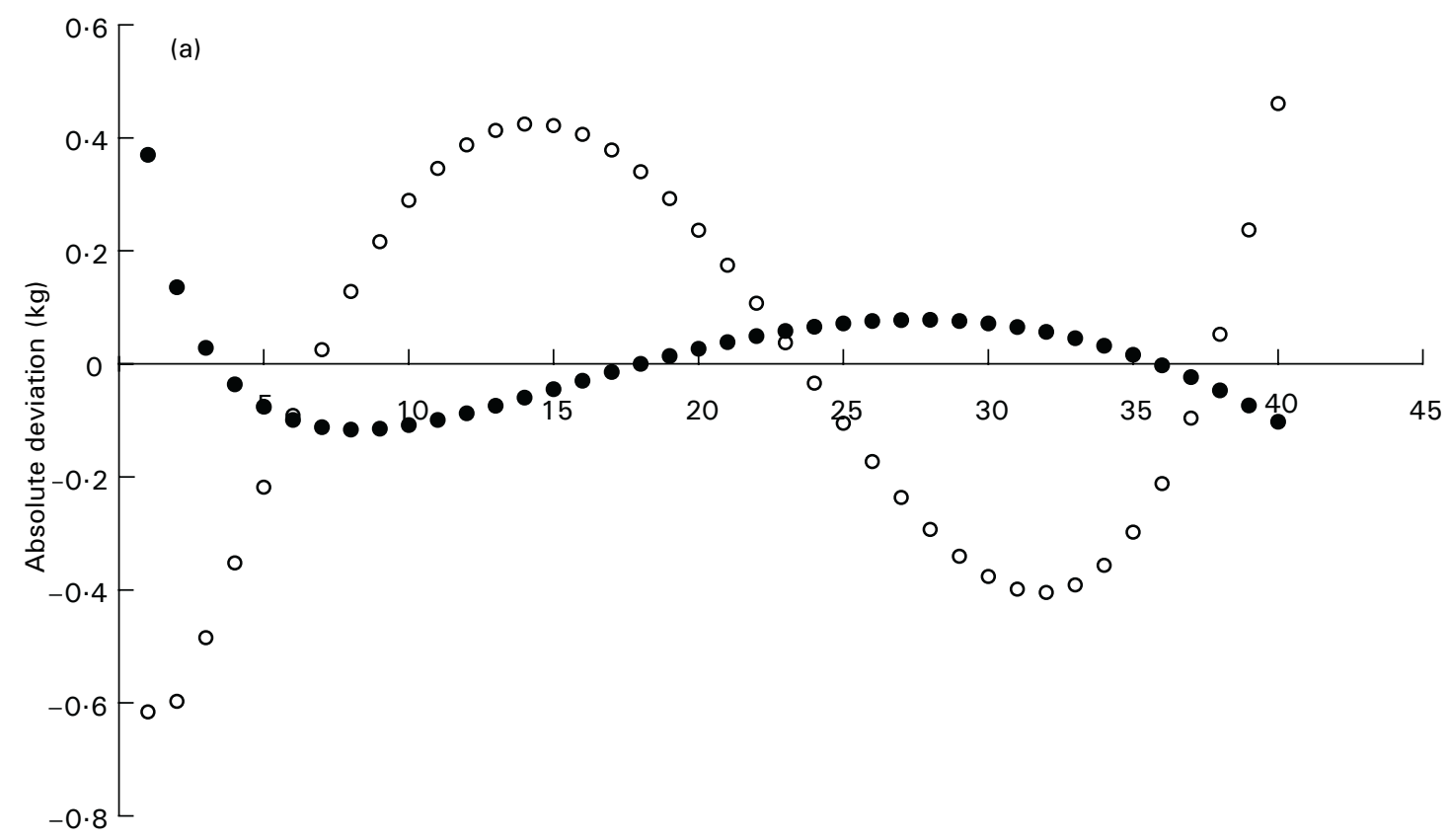

Protein weight $(\mathrm{kg})$

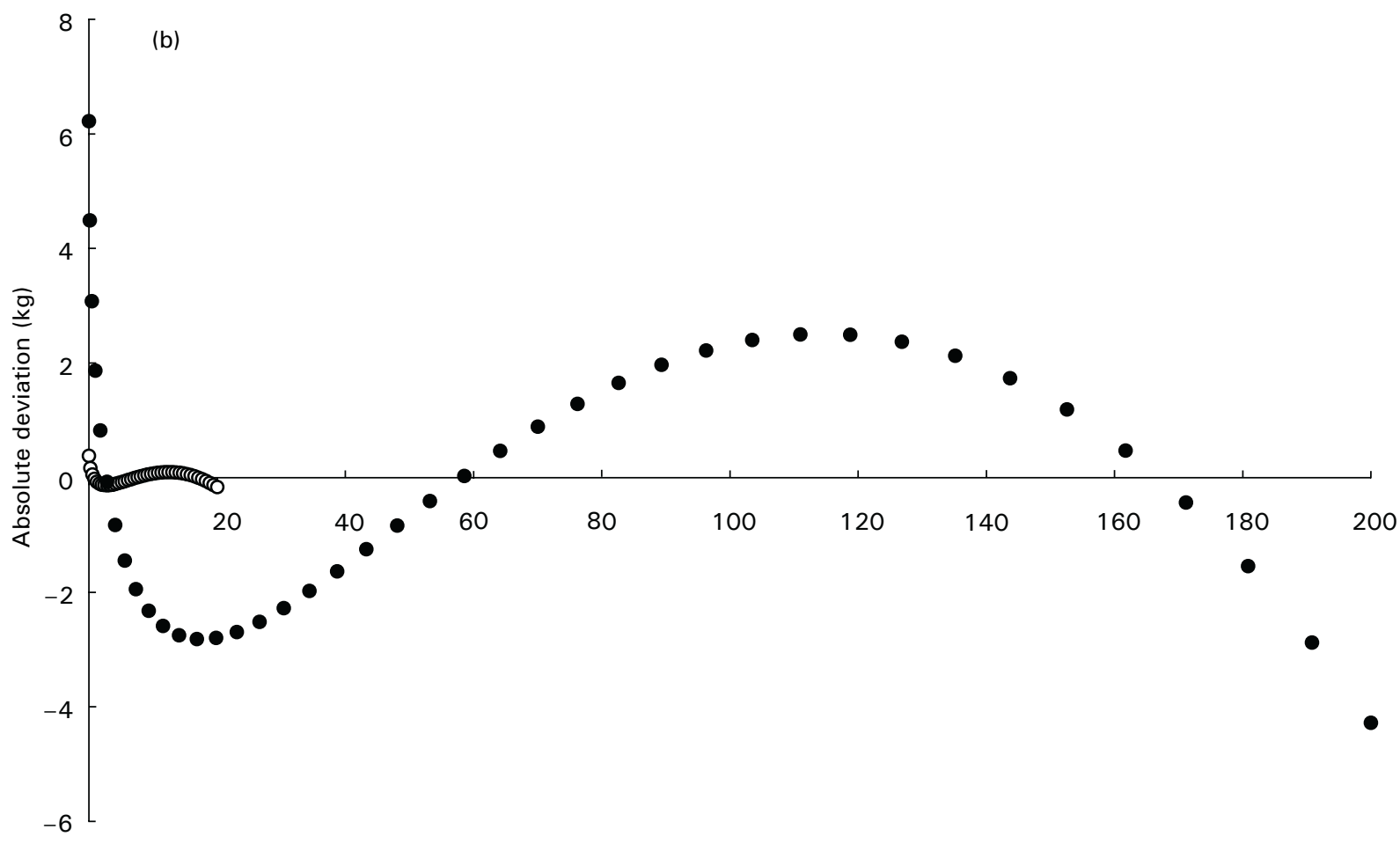

Lipid weight $(\mathrm{kg})$

Fig. 1. The systematic deviation produced when a quadratic function is used to describe the relationship between protein weight and live weight (a), and between lipid weight and live weight (b) at a mature lipid:protein of $0.5(0)$ and $5.0(\bullet)$.

given in Table 1. These relationships were used to estimate the composition of the gain of a pig with a given value of $\mathrm{LPR}_{\mathrm{m}}$ at a given weight.

Estimation of the energy and intake parameters. The value of the parameter $x$, used to determine the maximum capacity for WHC in equation (6), was calculated from the data of Whittemore et al. $(2001 b, c)$. Food intake $/ \mathrm{kg}$ live weight per $\mathrm{d}$ (scaled food intake) was regressed on the reciprocal of the WHC values for a range of bulky foods. The value of $x$ was estimated to be 0.27 (Table 1 ). This value is 
Table 1 (a). The equations and parameter values used to predict changes in food intake over time during the period of adaptation to a new food

\begin{tabular}{|c|c|c|c|c|c|}
\hline Component & Equation & Parameter & Value & Units & Reference \\
\hline$(\mathrm{dW} / \mathrm{dt})_{\max }$ & $(\mathrm{dW} / \mathrm{dt})_{\max }=\mathrm{B} \times \mathrm{W} \times \log _{\mathrm{e}}(\mathrm{A} / \mathrm{W})$ & $A$ & 250 & $\mathrm{~kg}$ & Knap (2000) \\
\hline$(\mathrm{dW} / \mathrm{dt})_{\max }$ & $(\mathrm{dW} / \mathrm{dt})_{\max }=\mathrm{B} \times \mathrm{W} \times \log _{\mathrm{e}}(\mathrm{A} / \mathrm{W})$ & $\mathrm{B}$ & 0.013 & $/ d$ & Emmans (1988); Knap (2000) \\
\hline $\mathrm{C}_{\text {whe }}$ & $\mathrm{C}_{\mathrm{whc}}=z \times \mathrm{W}$ & $z$ & 0.27 & Units/kg per d & Whittemore et al. $(2001 a, b)$ \\
\hline $\mathrm{EE}_{\mathrm{m}}$ & $\mathrm{EE}_{\mathrm{m}}=a \times \mathrm{W}$ & $a$ & 0.11 & $\mathrm{MJ} / \mathrm{kg}$ per d & Emmans \& Fisher (1986) \\
\hline ASH & $\mathrm{ASH}=k_{1} \times \mathrm{P}^{b}$ & $b$ & 1 & & Emmans \& Kyriazakis (1997) \\
\hline ASH & $\mathrm{ASH}=k_{1} \times \mathrm{P}^{b}$ & $k_{1}$ & $0 \cdot 2$ & & Emmans \& Kyriazakis (1997) \\
\hline WA & $\mathrm{WA}=k_{2} \times \mathrm{P}^{c}$ & $c$ & 0.855 & & Kotarbinska (1969) \\
\hline WA & $k_{2}=W A P R_{m} \times P^{1-c}$ & WAPR $_{m}$ & 3.04 & & Emmans \& Kyriazakis (1995) \\
\hline $\mathrm{L}$ & $d=1.46 \mathrm{LPR}_{\mathrm{m}^{0.23}}$ & $d$ & Variable & & Emmans (1997) \\
\hline $\mathrm{L}$ & $k_{3}=\mathrm{LPR}_{\mathrm{m}} \times \mathrm{P}_{\mathrm{m}^{1-d}}$ & $k_{3}$ & Variable & $\mathrm{kg} / \mathrm{kg}$ & Emmans (1997) \\
\hline \multirow[t]{2}{*}{ EE } & $\mathrm{EE}=\left(y_{1} \times \mathrm{P} / \mathrm{W}\right)+\left(y_{2} \times \mathrm{L} / \mathrm{W}\right)$ & $y_{1}$ & 50 & $\mathrm{MJ} / \mathrm{kg}$ & Emmans (1994) \\
\hline & & $y_{2}$ & 56 & $\mathrm{MJ} / \mathrm{kg}$ & Emmans (1994) \\
\hline
\end{tabular}

W, current body weight; B, rate parameter; A, mature body weight; whc, water-holding capacity; EE, effective energy; ASH, ash content; WA,

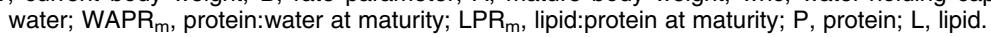

Table 1 (b). The equations and parameter values used to predict changes in body protein and lipid weights with a change in weight

\begin{tabular}{llcc}
\hline Component & \multicolumn{1}{c}{ Equation } & Parameter & Value \\
\hline $\mathrm{dP} / \mathrm{dW}$ & $\mathrm{dP} / \mathrm{dW}=b_{1}+2 c_{1} \mathrm{~W}$ & $b_{1}, c_{1}$ & $\mathrm{NA}$ \\
$\mathrm{dL} / \mathrm{dW}$ & $\mathrm{dP} / \mathrm{dW}=b_{2}+2 c_{2} \mathrm{~W}$ & $b_{2}, c_{2}$ & $\mathrm{NA}$ \\
$\mathrm{dP} / \mathrm{dW}$ & $b_{1}=g_{1}+\left(h_{1} \times \mathrm{LPR}_{\mathrm{m}}\right)+\left(j_{1} \times \mathrm{LPR}_{\mathrm{m}^{2}}\right)$ & $g_{1}$ & 0.196149 \\
& & $h_{1}$ & -0.004645 \\
& & $j_{1}$ & -0.0005750 \\
$\mathrm{dP} / \mathrm{dW}$ & $c_{1}=g_{2^{+}}\left(h_{2} \times \mathrm{LPR}_{\mathrm{m}}\right)+\left(j_{2} \times \mathrm{LPR}_{\mathrm{m}^{2}}\right)$ & $g_{2}$ & 0.000168 \\
& & $h_{2}$ & -0.00017 \\
& & $j_{2}$ & 0.000022 \\
$\mathrm{dL} / \mathrm{dW}$ & $b_{2}=g_{3}+\left(h_{3} \times \mathrm{LPR}_{\mathrm{m}}\right)+\left(j_{3} \times \mathrm{LPR}_{\mathrm{m} 2}\right)$ & $g_{3}$ & 0.045183 \\
& & $h_{3}$ & 0.050894 \\
& & $j_{3}$ & -0.00034 \\
$\mathrm{dL} / \mathrm{dW}$ & $c_{2}=g_{4}+\left(h_{4} \times \mathrm{LPR}_{\mathrm{m}}\right)+\left(j_{4} \times \mathrm{LPR}_{\mathrm{m}^{2}}\right)$ & $g_{4}$ & 0.0000504 \\
& & $h_{4}$ & 0.000468 \\
& & $j_{4}$ & -0.0000670 \\
\hline
\end{tabular}

P, protein; W, weight; NA, not applicable; LPR $_{m}$, lipid:protein at maturity.

higher than that suggested by Kyriazakis \& Emmans (1995) but comparable to the value suggested by Tsaras et al. (1998) and may reflect differences in the methodology used to estimate WHC. The value of $a$ in equation (3) used to calculate the amount of energy required for maintenance is estimated to be $0 \cdot 11$. It was calculated using the rule of Emmans \& Fisher (1986) for scaling maintenance assuming a constant body protein content of $17 \%$. The model is not sensitive to the assumptions made about the energy requirements for maintenance. The values of the parameters $z_{1}$ and $z_{2}$ used in equation (16) to determine the amount of energy required/unit of gain were assumed to be 50 and $56 \mathrm{MJ} / \mathrm{kg}$ respectively (Emmans, 1994).

\section{Dynamic model}

The static model (equations (1) to (21)) allows the weight at the end of the day $\left(\mathrm{W}_{1}\right)$ to be calculated as:

$$
\mathrm{W}_{1}=\mathrm{W}_{0}+\Delta \mathrm{W}
$$

where with the time step of a day $\Delta \mathrm{W}$ stands for $\mathrm{dW} / \mathrm{dt}$ and $\mathrm{W}_{0}$ is the initial weight. To make the model dynamic, so that equilibrium food intake and growth rate can be predicted over time, the initial weight of the current day is made to equal the final weight of the preceding day. The static model can then be run again so that intake and growth rate on the current day is estimated, the final weight of that day then becomes the initial weight of the next day and so forth. In this way the model continues to update on a daily basis. It is recognised that updating the model on a daily basis will introduce some degree of error into the model (GC Emmans, unpublished results). However the size of this error will be small and for the purposes of the model the time step of a day is adequate.

\section{Modelling the transition from one food to another}

General. The overall aim of the model is to describe the transition to a new equilibrium intake when a change in food type, from one food to another with a different bulk content, occurs. The dynamic model described above predicts the food intake and growth rate for a given pig over time, assuming that food intake is always at equilibrium, i.e. that the pig is fully adapted to the food that it is on. However, when a change in food occurs, from one 
food to another of higher bulk content there will be a period of adaptation during which food intake will gradually increase until the new equilibrium on the new food is reached. The dynamic model described earlier (p. 388) makes no attempt to predict changes in food intake and growth rate during such a period of adaptation. Two problems need to be solved to make the model transitory. The first is that the level of food intake on the first day following the change (i.e. the extent to which food intake is initially reduced) must be predicted. Second, the model must predict the time course of adaptation, that is, how long it will take for a pig to become adapted to the new food and to reach its new equilibrium intake.

An animal is considered to have a current capacity to consume food bulk (WHC) which is dependent upon the WHC of the food fed and the length of time that the animal has been on that food so that:

$$
\mathrm{C}_{\mathrm{whc}}=((\mathrm{FI} \times \mathrm{WHC}) / \mathrm{W})+(v \times \mathrm{t}) \mathrm{kg} / \mathrm{kg},
$$

where FI is food intake, $\mathrm{W}$ is weight, $\mathrm{t}$ is time (d) and $v$ is the daily rate of change in capacity after the changeover. It is proposed that the capacity for WHC on the first day following a change in food will be determined by the WHC of the food fed before the change. When an animal is changed from its current food to another food of higher bulk content, capacity for WHC is not expected to change immediately. It is therefore assumed that the capacity for WHC on the first day of the new food will be equal to the current capacity for WHC on the last day of the previous food. Thereafter, capacity for WHC will gradually increase over time as the gastrointestinal tract becomes adapted to the new food being fed (Kyriazakis \& Emmans, 1995; Tsaras et al. 1998). The rate of change, $v$, is assumed to be the same for all pigs regardless of the food being fed and the increase in capacity over time is assumed to be linear. The available literature on this area is scarce, as in most cases the period of adaptation is not considered. However, the experimental evidence that is available (Kyriazakis \& Emmans, 1995; Tsaras et al. 1998) gives no reason to reject the assumptions put forward. Capacity for bulk after the changeover will therefore be increased to a maximum of $x$ by $v$ units/d.

New parameter values. Previous work (Tsaras et al. 1998) has shown that adaptation when moving from a food with a WHC of approximately $4 \mathrm{~kg} / \mathrm{kg}$ dry food to a constraining food with a WHC of approximately $8 \mathrm{~kg} / \mathrm{kg}$ dry food takes about $12 \mathrm{~d}$. Therefore, we assume that a pig changing from a food with a WHC of $0 \mathrm{~kg} / \mathrm{kg}$ dry food to a constraining food $(8 \mathrm{~kg} / \mathrm{kg}$ dry food) will take about $23 \mathrm{~d}$ to adapt to the new food. The maximal capacity for bulk was estimated by Tsaras et al. (1998) to be 0.23 units $/ \mathrm{kg}$ per $\mathrm{d}$. Consequently, the rate parameter $z$ is initially assumed to have a value of $0 \cdot 01$ units/d, calculated as $0 \cdot 23 / 23$.

\section{Testing the model}

The model was set up to simulate experiments where an average pig with a given $\mathrm{LPR}_{\mathrm{m}}$ is changed from one food to another with a different bulk content. The model calculates food intake and live-weight gain throughout the course of the experiment so that changes in food intake and live-weight gain with changes in food type can be monitored.

Preliminary testing of the model was achieved by comparing predicted responses from the model with those recorded in the real system. The data used to evaluate the performance of the model were taken from two studies (Kyriazakis \& Emmans, 1995; Whittemore et al. 2002) that reported the food intake and performance of growing pigs fed a series of two foods differing in bulk content. In both cases the foods contained varying levels of either unmolassed sugar-beet pulp (SBP) or wheat bran (WB). The model was set up to roughly repeat these experiments. The initial weight, final weight and the live weight at which the food was changed, and the percentage of SBP and WB in each of the foods, were inputs to the model. The model was set up so that the relevant food composition variables dietary energy (DE), crude protein (CP) and WHC were calculated from the percentages of SBP and WB in the food so that:

$$
\begin{gathered}
\mathrm{DE}=13.2-(0.03 \times \mathrm{SBP})-(0.046 \times \mathrm{WB}) \mathrm{MJ} / \mathrm{kg}, \\
\mathrm{CP}=235-(0.0534 \times \mathrm{SBP})-(0.819 \times \mathrm{WB}) \mathrm{g} / \mathrm{kg} \\
\mathrm{WHC}=3.5+(0.093 \times \mathrm{SBP}) \\
+(0.013 \times \mathrm{WB}) \text { units } / \mathrm{kg} .
\end{gathered}
$$

The relationships between the percentages of SBP and WB and the food composition variables were estimated by regressing $\mathrm{DE}, \mathrm{CP}$ and $\mathrm{WHC}$ on the percentage of SBP and WB in the food (data taken from Whittemore et al. 2001b,c). SBP and WB are the only two raw materials considered here but the model can be adapted for use with any raw material. DE was then converted to ME by:

$$
\mathrm{ME}=(0.997 \mathrm{DE})-(0.000189 \mathrm{CP}) \mathrm{kJ} / \mathrm{kg} .
$$

EE was then calculated (Emmans, 1994) as:

$$
\mathrm{EE}=1 \cdot 17 \mathrm{ME}-4.49 \mathrm{CP}-2.44 \mathrm{~kJ} / \mathrm{kg},
$$

where $\mathrm{ME}$ is in $\mathrm{kJ} / \mathrm{kg}$, and $\mathrm{CP}$ is in $\mathrm{g} / \mathrm{g}$.

Fig. 2 shows the individual intakes of a group of pigs during the change over from one food to another of higher bulk content. The variation between pigs is large. This is relevant when comparing the agreement between the predictions of the model and the mean of the observed data.

\section{Results \\ Moving from a control food to a bulky food}

Fig. 3 shows the predicted and observed food intakes on a change from a control (non-limiting, non-bulky) food to one of higher bulk content. Qualitatively the predictions of the model are in agreement with the measured data of both Kyriazakis \& Emmans (1995) and Whittemore et al. (2002). The model predicts that as the difference in bulk content between the first and second food increases so 


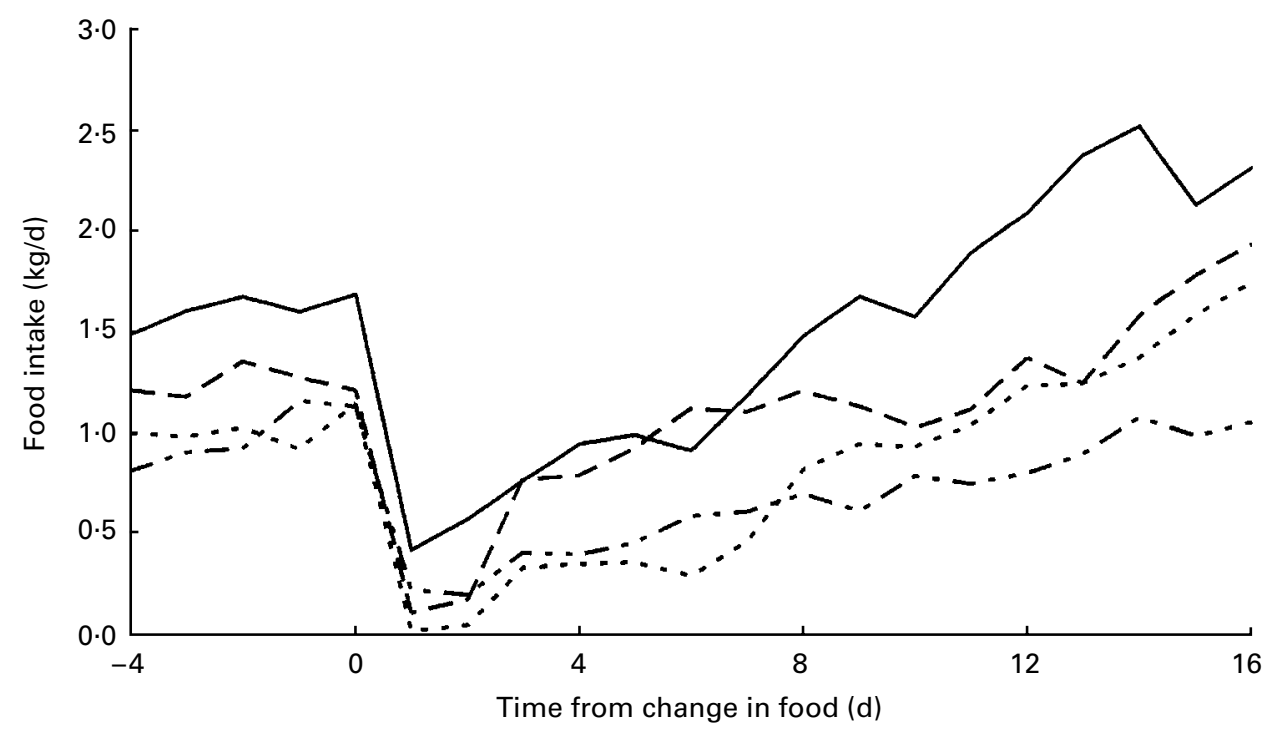

Fig. 2. Observed food intakes of four pigs changed from a control food to a $97 \%$ wheat-bran food. (Data from Kyriazakis \& Emmans, 1995.)

does the initial reduction in food intake after the change. However, the model consistently under-predicts extent of the initial reduction in food intake and hence over-predicts food intake on the bulky food when there is a change to a food high in WB.

\section{Moving from a less to a more bulky food}

The predictions of the model are in good qualitative agreement with the measured data when the change is from a less to a more bulky food (Fig. 4). The predictions of the model are in better quantitative agreement with the data of Kyriazakis \& Emmans (1995; Fig. 4(a)), when there is a change from a $48 \% \mathrm{WB}$ to a $97 \%$ WB food, than with those of Whittemore et al. (2002; Fig. 4(b)). In the latter case there was a change from a $70 \% \mathrm{WB}$ to a $70 \% \mathrm{SBP}$ food. However, for the data of Kyriazakis \& Emmans (1995) the model under-predicts the extent of the initial reduction in intake after the change. A consequence is that the model over-predicts intake after the change. For the data of Whittemore et al. (2002) the model accurately predicts the initial reduction in food intake after the change in food, but consistently and significantly under-predicts food intake on the more bulky food (70\% SBP).

\section{Moving from a more to a less bulky food}

The model predicts the pattern of food intake during such a change with reasonable accuracy (Fig. 5). The predictions of the model are in good agreement with the data of Kyriazakis \& Emmans (1995, Fig. 5(a)), where there is a change from a $97 \% \mathrm{WB}$ food to a $48 \% \mathrm{WB}$ food. Here the model shows good qualitative and quantitative agreement with the measured data. The model shows good qualitative agreement with the measured data of Whittemore et al. (2002; Fig. 5(b)), but again under-predicts food intake on the less bulky food $(70 \% \mathrm{WB})$.

\section{Discussion}

The aim was to construct a model that could predict intake during the period of adaptation following a change in food type. The assumptions made in the dynamic model, which predicts changes in equilibrium intake over time, were derived from the current literature on dynamic food intake prediction models (Emmans \& Fisher, 1986; Emmans, 1988, 1994, 1997; Emmans \& Kyriazakis, 1995, 1997; Kyriazakis \& Emmans, 1995, 1999; Tsaras et al. 1998). The model was then adapted to be able to deal not only with intakes when the pig was at equilibrium with its food, but also during the adaptation period to a new food. Most current models to predict food intake do not consider adaptation to a change in food. The adapted model is an initial attempt at describing and quantifying this phenomenon.

\section{Assumptions made in the model}

For the purposes of the model it is assumed that the composition of the gain of a given kind of pig at a given weight is unaffected by the type of food being fed. It is recognised that this assumption may not always be correct. It is possible, for example, that on unbalanced foods there will be some differences in composition of gain between foods (Kyriazakis et al. 1991; Kyriazakis \& Emmans, 1992a,b). Given that the model is intended to be used only for balanced foods it is likely that any differences in composition of gain between foods will be small enough to be ignored for the present purposes.

The value of the constant $x$ in equation (6) is crucial for calculating a CFI. In the current model the value of $x$ was 

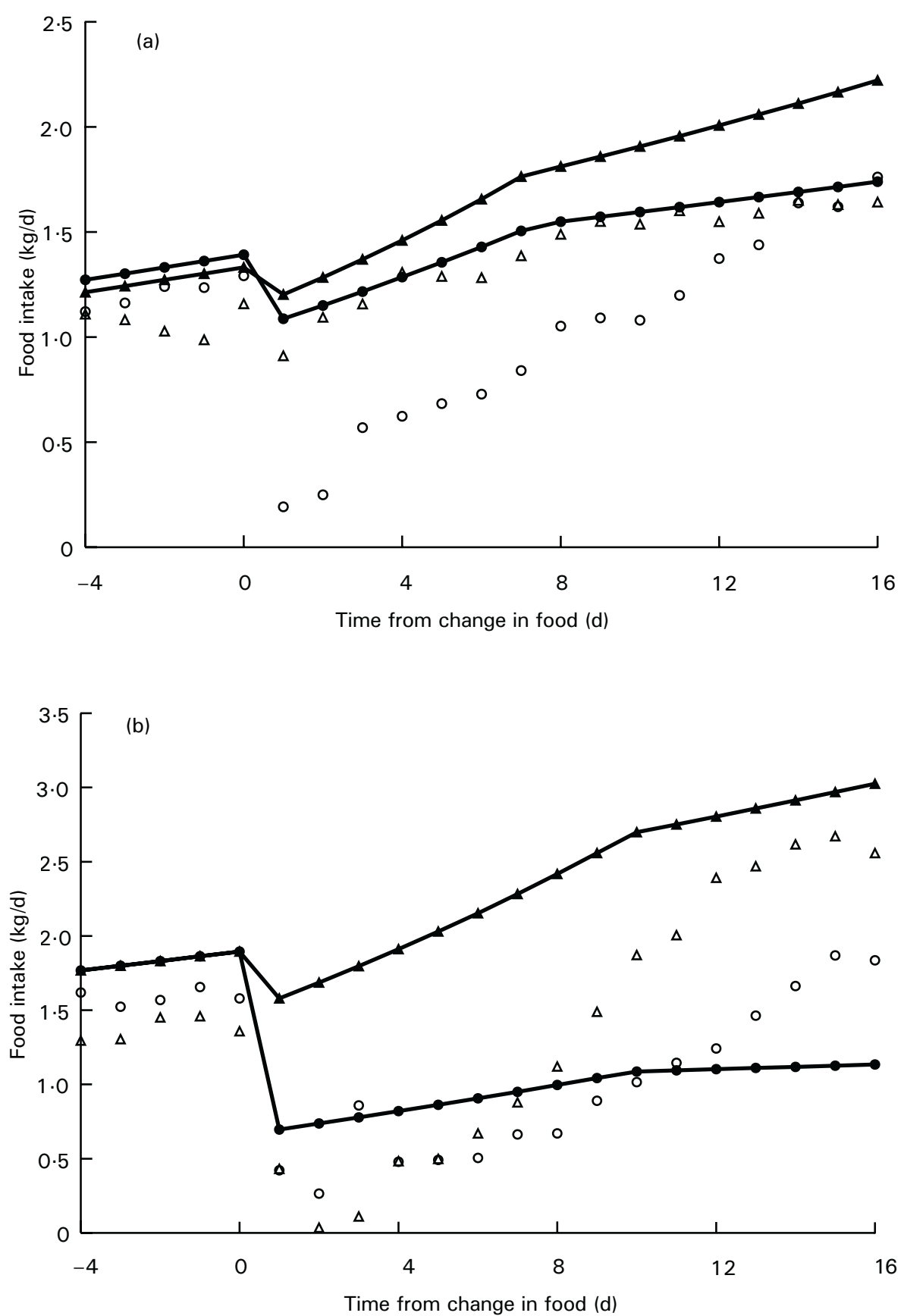

Fig. 3. Observed $(O, \Delta)$ and predicted $(\bullet, \mathbf{\Lambda})$ intakes when there is a change from a control food to (a), either a $97 \%(O, \bullet)$ or a $48 \%(\Delta, \mathbf{\Lambda})$ wheat-bran food (data from Kyriazakis \& Emmans, 1995); (b), either a $70 \%$ sugar beet-pulp food $(\mathrm{O}, \bullet)$ or a $70 \%$ wheat-bran food $(\triangle, \mathbf{\Lambda})$ (data from Whittemore et al. 2002).

estimated from the work of Whittemore et al. $(2001 b, c)$ to be 0.27 units $/ \mathrm{kg}$ per $\mathrm{d}$. This is substantially higher than the value of 0.17 estimated by Kyriazakis \& Emmans (1995), but closer to the value of 0.23 estimated by Tsaras et al. (1998). The variation in estimates of the value of $x$ between these cases may be due to differences in the methodology used to measure WHC.

The parameter $z$ is the rate at which the pig's capacity for WHC increases during adaptation. The value of $z$ was estimated from the data of Tsaras et al. (1998) to be 0.01 units/d. It is assumed that the rate of change is the same for all pigs regardless of the food being fed and that the increase in capacity over time is linear. It is recognised that the value of constant $z$ and the assumptions made about it may not be correct. However, as a first step the value chosen for $z$ and the assumptions made about it seem reasonable, based on evidence in the literature.

\section{Moving from a control to a more bulky food}

Qualitatively the predictions of the model agree quite well, but far from perfectly, with the measured data when the 

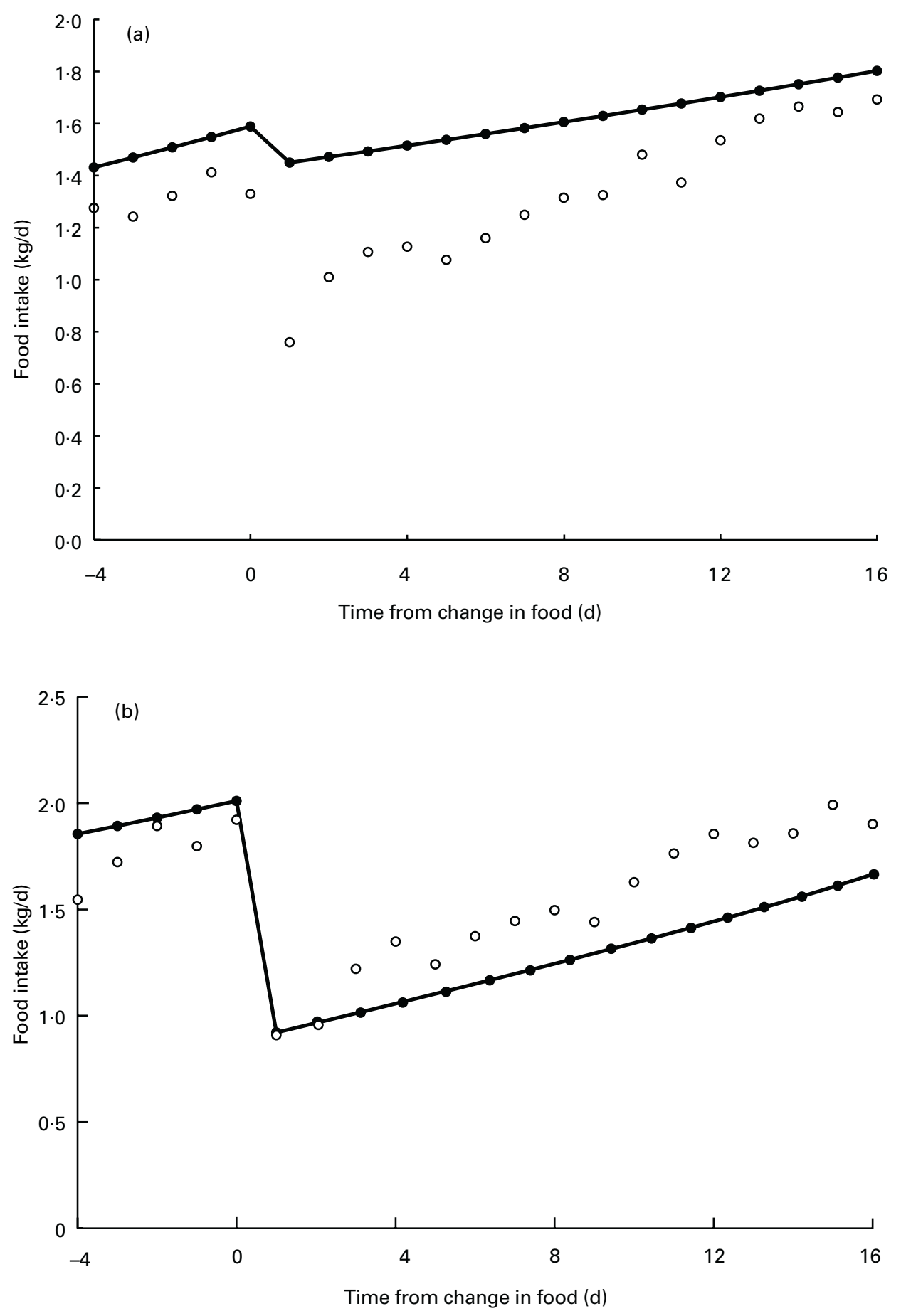

Fig. 4. Observed $(O)$ and predicted intakes $(\bullet)$ when there is a change (a), from a $48 \%$ wheat-bran to a $97 \%$ wheat-bran food (data from Kyriazakis \& Emmans, 1995); (b), from a $70 \%$ wheat-bran to a $70 \%$ sugar beet-pulp food (data from Whittemore et al. 2002).

change is from a control to a more bulky food (Fig. 3). The model predicts that there will be an initial reduction in intake. The reduction is also predicted to increase as the difference in the bulk content between the two foods is increased. However, the model significantly under-predicts the extent to which intake is reduced on the first day after the changeover and hence overestimates intake thereafter, particularly when the change is to a food based on WB (see Fig. 3). In the model the only measure of bulk is WHC and this was found to be sufficient to account for differences in equilibrium intakes (Kyriazakis \& Emmans, 1995; Tsaras et al. 1998). The differences in WHC between the control food and the WB foods of Kyriazakis \& Emmans (1995) and Whittemore et al. (2002) are not large. The control food had $3.50 \mathrm{~g}$ water/g dry food while the $48 \% \mathrm{WB}$ had $4.12 \mathrm{~g}$ water/g dry 

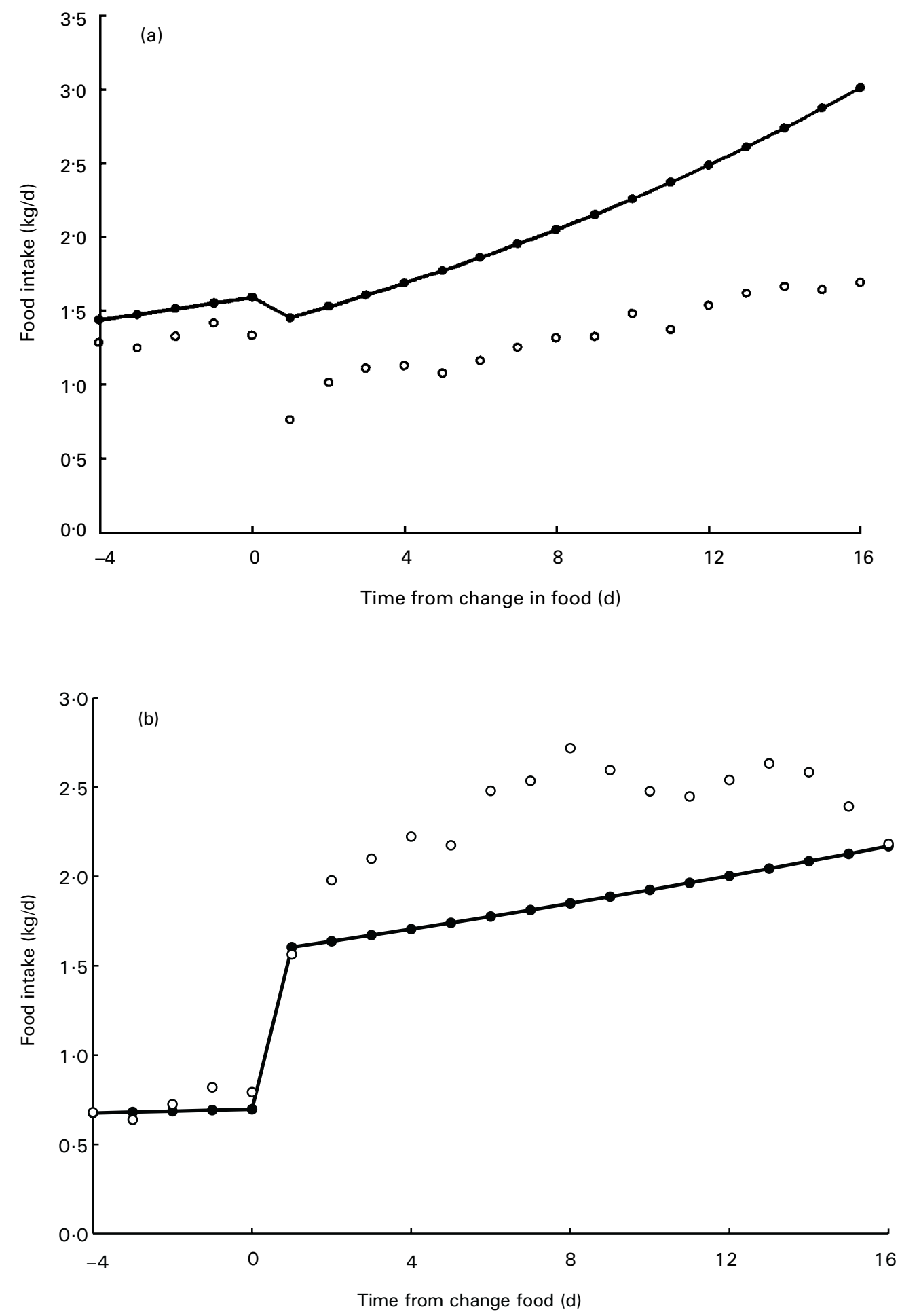

Fig. 5. Observed $(O)$ and predicted $(\bullet)$ intakes when there is a change (a), from a $97 \%$ wheat-bran to a $48 \%$ wheat-bran food (data from Kyriazakis \& Emmans, 1995); (b), from a $70 \%$ sugar beet-pulp to a $70 \%$ wheat-bran food (data from Whittemore et al. 2002).

food, the $70 \% \mathrm{WB}$ had $4.41 \mathrm{~g}$ water/g dry food and the $97 \% \mathrm{WB}$ had $4.76 \mathrm{~g}$ water/g dry food. When there is only a small difference in WHC between the foods the model predicts a relatively small reduction in food intake after the changeover. The measured data, where the actual reduction in food intake is much greater than that predicted by the model, suggest that there may be other factors not considered in the model that are important for the control of intake on food with high contents of WB. WB has a low digestibility (Ehle et al. 1982; Nyman \& 
Nils-Georg, 1982; Noblet \& Bach Knudsen, 1997) with a high level of insoluble, lignified fibre (Ehle et al. 1982; Selvandran, 1984; Noblet \& Bach Knudsen, 1997). This fibre is resistant to degradation in the gastrointestinal tract and is only slowly available for fermentation (Noblet \& Bach Knudsen, 1997). The large reduction in intake seen following a change to a food with a high WB content may thus be due to the fact that the guts of the pigs are not initially adapted for the digestion of this material. It is unlikely that the microbial population necessary for the efficient digestion of WB will exist immediately following the change. It has been shown that pigs fed high-fibre diets have an increased number of cellulose-degrading bacteria, and that the cellulolytic activity increases over time (Varel, 1987). The change needed in the microflora population, in order to degrade WB efficiently, can be acquired only over time, as the animal becomes adapted to the food. The model does not account for the fact that different foods may require different amounts of time to reach an equilibrium rate of digestion. In fact, the model does not account for digestion at all, except by using DE values from food tables, which are presumably equilibrium values. Where the ability to digest WB is important for the control of intake then the model will necessarily under-predict the initial reduction in intake after a change to a food with a high content of WB. The problem does not exist when the change is from a control food to one based on SBP (Fig. 3(b)). The immediate problems of digesting a food based on SBP are unlikely to be the same as those for a food based on WB. SBP is a highly digestible material (Nyman \& NilsGeorg, 1982). Its high level of pectic polysaccharides enhances microbial attachment allowing a high level of microbial activity, while the high WHC causes swelling which increases the surface area available to the microflora of the gut. All these factors facilitate colonisation and degradation of the substrate (Noblet \& Bach Knudsen, 1997). If WHC, rather than the ability to digest SBP, determines intake then the model should be able to accurately predict the initial reduction after a change to a SBP food. The evidence (Fig. 3(b)) is that it does.

Animals are sometimes said to avoid a food that is new to them, i.e. to show 'neophobia' (Provenza \& Balph, 1987; Forbes, 2001). It could be suggested that pigs initially avoided the foods with a high content of WB because it was new to them and they were neophobic. However, if the pigs were neophobic in this case, then they must be expected to be neophobic in general. But they did not show a reduced intake when transferred to the control food after long periods on the foods of high fibre content (Kyriazakis \& Emmans, 1995; Whittemore et al. 2002). They therefore cannot be seen as being neophobic in general, and neophobia cannot account for the initial reduction in intake when there is a change to a new food high in WB.

\section{Moving from a less to a more bulky food}

The predictions from the model for such a change (Fig. 4) are also in qualitative agreement with the measured data. As before, however, the model under-predicts the reduction in intake for foods based on $\mathrm{WB}$, and a consequence of this is that it over-predicts food intake during the initial few days after the changeover. A likely reason for this discrepancy between the model predictions and the observed data has been discussed earlier. The model is able to predict with a high degree of accuracy the initial reduction in food intake when there is a change from a $70 \%$ WB food to a $70 \%$ SBP food (Fig. 4(b)). Thereafter, however, the model significantly under-predicts food intake on the SBP-based food. The reason for this discrepancy is not clear, but it is also seen to occur when there is a change from a control food to a $70 \%$ SBP food (Fig. 3(b)). It is assumed in the model that there is a maximum capacity for bulk $(0.27$ units/kg per d) which cannot be exceeded and that actual capacity will be increased by 0.01 units/d until the maximum is reached. For this particular case, when there is a change in food from a $70 \%$ WB food to a $70 \%$ SBP food, the model predicts that the maximum capacity for bulk will have been reached by the time that the change in food occurs. In the experiment of Whittemore et al. (2002) pigs were fed the WB food for a period of $21 \mathrm{~d}$ before the changeover. The increase in intake over time on the SBP food is therefore the result of an increase in live weight. The observed data show that in reality pigs are able to consume significantly more of the SBP food than would have been expected according to the results from other work completed in this area (Kyriazakis \& Emmans, 1995; Tsaras et al. 1998; Whittemore et al. 2001b). It may be that their ultimate capacity for bulk, at least as SBP, is much greater than is assumed in the model. If it is assumed that there is no maximum capacity, and that capacity for bulk increases indefinitely at a rate of 0.01 bulk units/d, then the model predictions are in much better agreement with the observed data (Fig. 6) for a change from a food with $70 \% \mathrm{WB}$ to one with $70 \%$ SBP. Here the model is able to accurately predict food intake on a $70 \%$ SBP food. Despite the good fit of the model to the observed data when there is a change from a $70 \% \mathrm{WB}$ to a $70 \% \mathrm{SBP}$ food, the assumption that there is no maximum capacity for bulk does not account for the data when there is a change from a $48 \% \mathrm{WB}$ food to a $97 \% \mathrm{WB}$ food (Kyriazakis \& Emmans, 1995; Fig. 7). Therefore, this assumption cannot be considered to be general. The validity of the assumption that there is no maximum capacity for bulk must also be questioned. It does not seem sensible to assume that the capacity for bulk will increase ad infinitum.

\section{Moving from a more to a less bulky food}

The model provides a very accurate fit to the observed data of Kyriazakis \& Emmans (1995) when the change is from a food with $97 \% \mathrm{WB}$ to one with $48 \%$ WB (Fig. 5(a)). However, the model under-predicts the intake of a $70 \%$ WB food when the change is from one with $70 \%$ SBP food using the data of Whittemore et al. (2002; Fig. 5(b)). This discrepancy can probably be attributed to the fact that the model makes no attempt to account for any compensatory increases in food that may occur when moving from a bulky food to one of improved quality. 


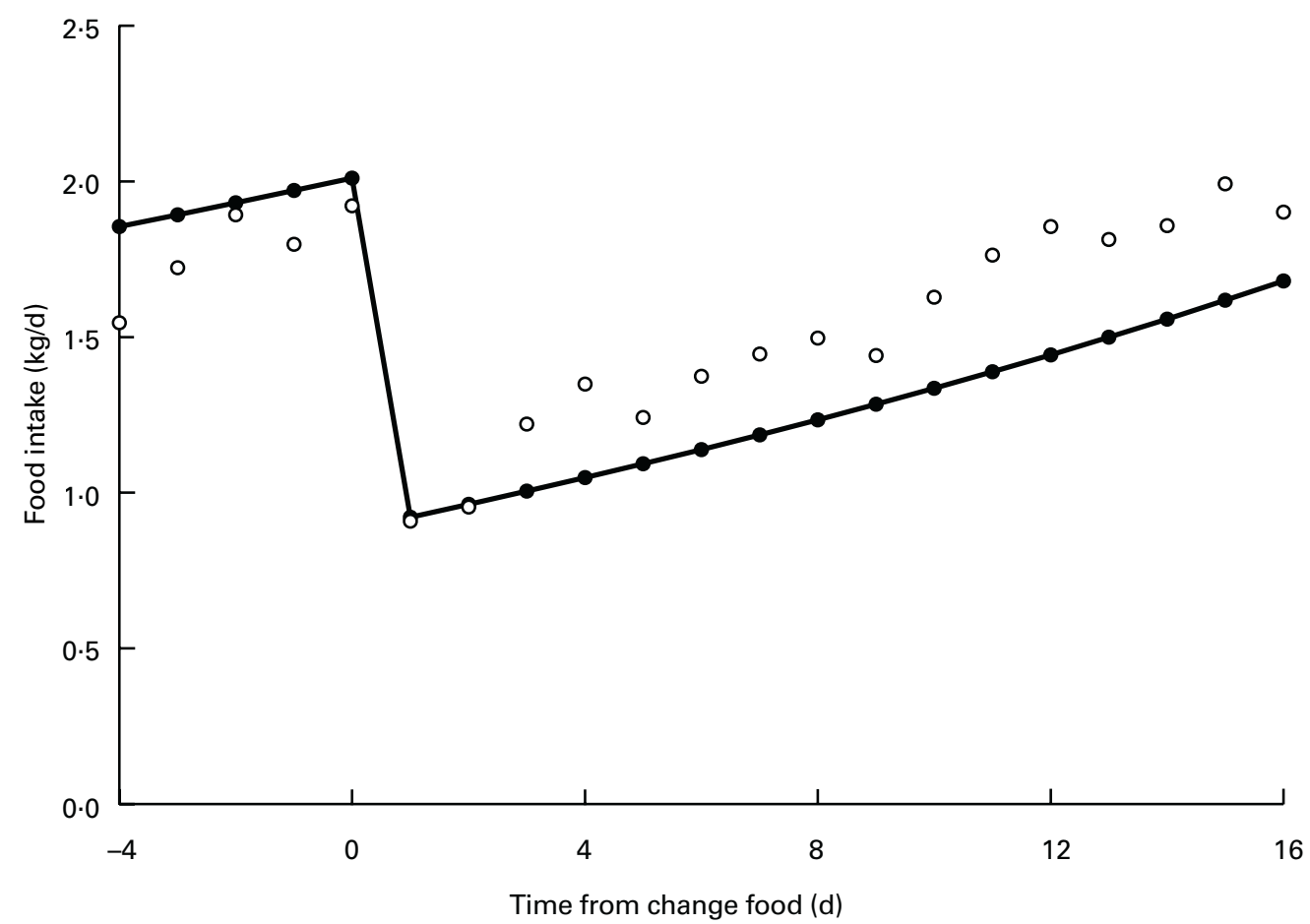

Fig. 6. Observed $(O)$ and predicted $(\bullet)$ intakes when there is a change from a $70 \%$ wheat-bran to a $70 \%$ sugar beet-pulp food. The predicted data are those produced by the model when it is assumed that there is no maximum capacity for bulk. (Data from Whittemore et al. 2002.)

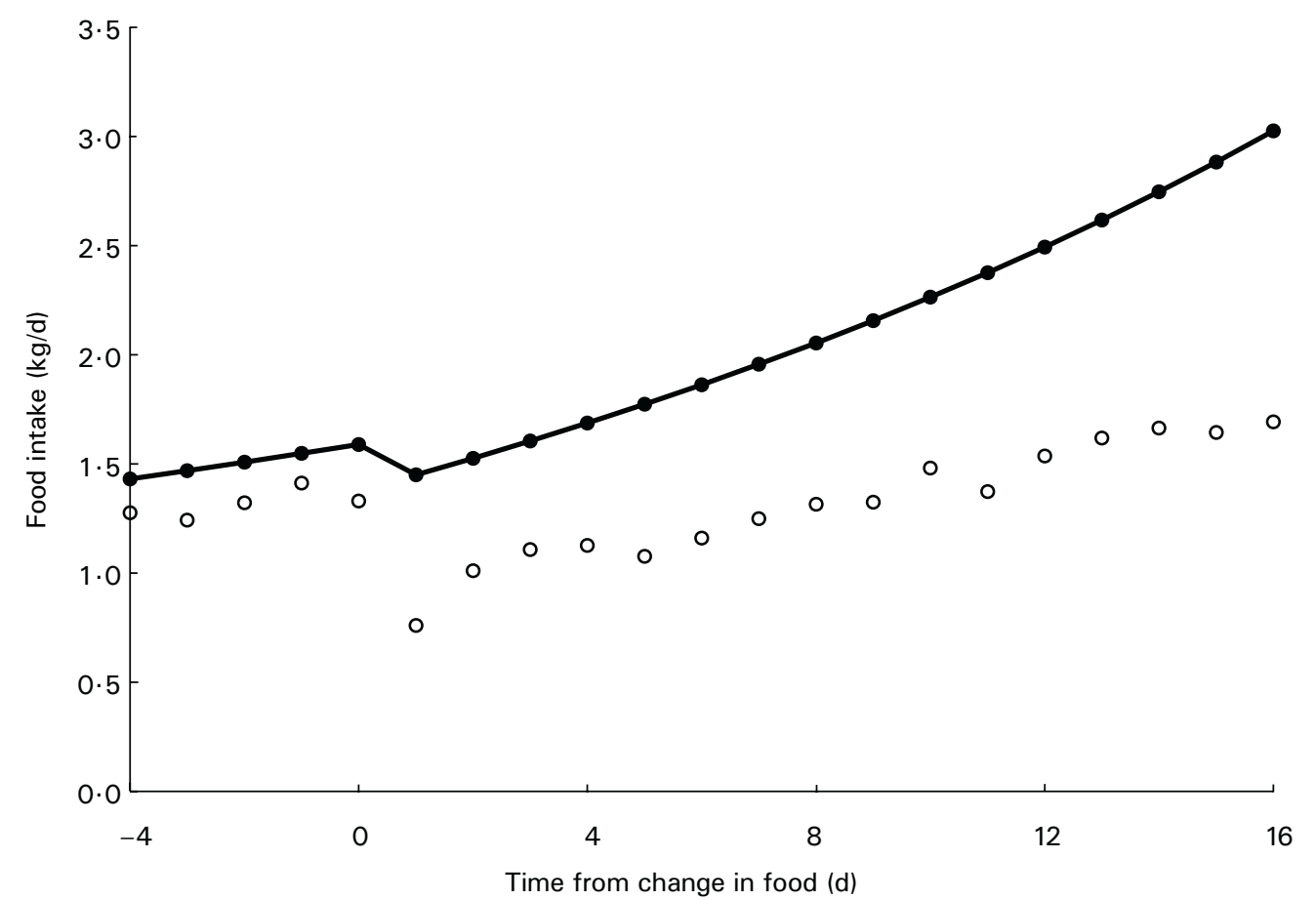

Fig. 7. Observed $(O)$ and predicted $(\bullet)$ intakes when there is a change from a $48 \%$ wheat-bran to a $97 \%$ wheat-bran food. The predicted data are those produced by the model when it is assumed that there is no maximum capacity for bulk. (Data from Kyriazakis \& Emmans, 1995.) 


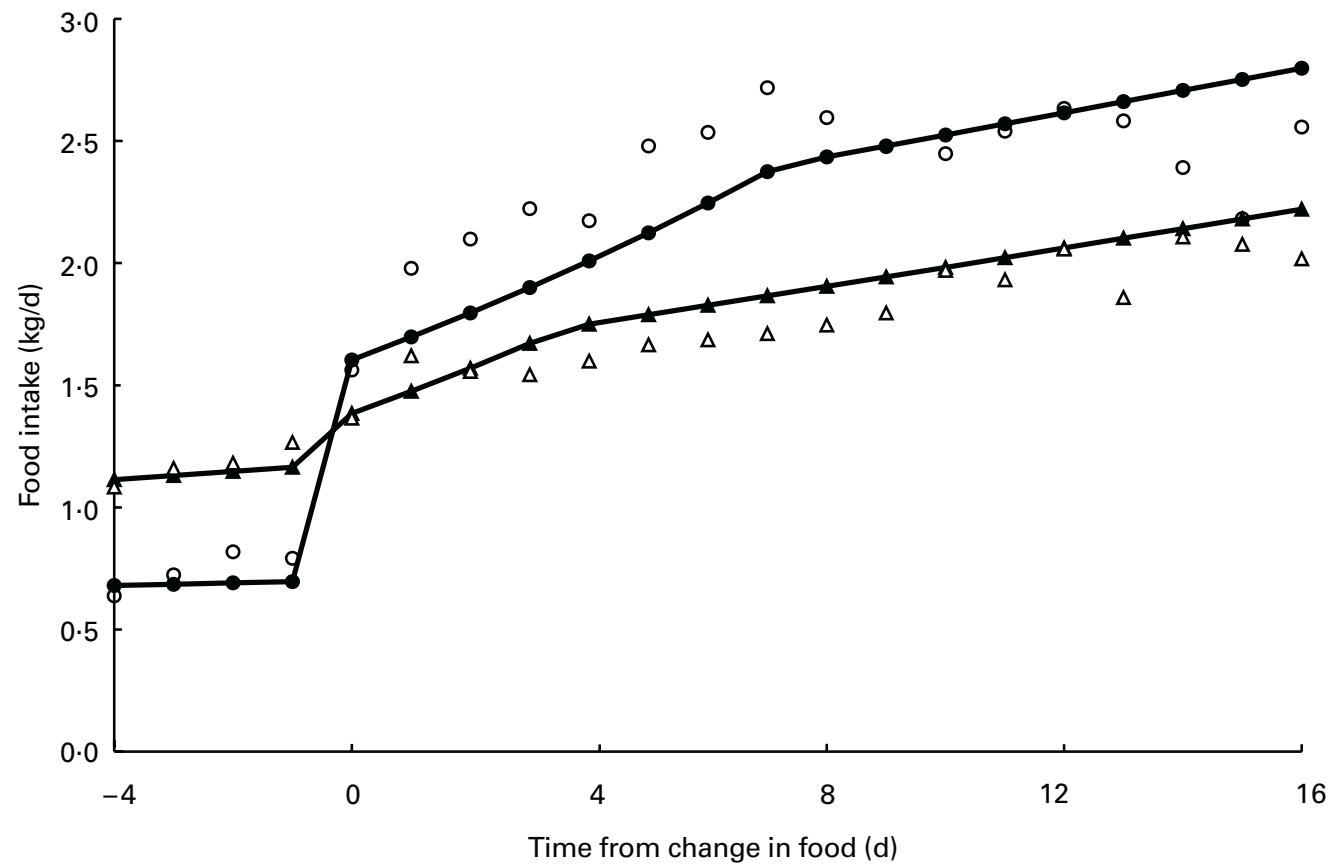

Fig. 8. Observed $(O, \Delta)$ and predicted $(\bullet, \Delta)$ intakes when there is a change from a $70 \%$ sugar beet-pulp food to a $70 \%$ wheat-bran food $(O, \bullet)$ or from a $97 \%$ wheat-bran food to a $48 \%$ wheat-bran food $(\triangle, \boldsymbol{\Lambda})$. The predicted data are those produced assuming that there is no maximum capacity for bulk. (Data from Kyriazakis \& Emmans, 1995; Whittemore et al. 2002.)

It has been shown that when animals are released onto a food of improved quality after a period of feeding on a high-bulk food, subsequent compensatory intakes and gains occur (Robinson, 1964; Owen et al. 1971; Stamataris et al. 1985; Whittemore et al. 2001b). The data of Whittemore et al. (2002) show that the $70 \% \mathrm{WB}$ food was not a constraining food when fed under the circumstances depicted in Fig. 5(b). It therefore seems likely that when pigs were moved from the SBP food onto the WB food that some compensatory increase in intake and gains would occur and certainly the food intake data seem to suggest that this is the case. Under conditions where compensation occurs the model would be expected to under-predict intake on the second food because it does not account for the occurrence of compensatory increases in intake. For the same reason the model would not be expected to be able to accurately predict changes in food intake over time when a change from a bulky food to a control food occurs. Here, also, compensatory increases in intake would be expected to occur (Whittemore et al. 2001c). To predict changes in intake when there are increases in intake to support compensatory gains are outside the scope of this model. To deal properly with this failure the assumption of constant composition of the gain would need to be relaxed and the partition of energy intake dealt with in a more realistic way.

Fig. 8 shows the model predictions when a change from a bulky food to a less bulky food is considered and the assumption that there is no maximum capacity for bulk is made. Here, the model predictions show good agreement with the observed data. The reason for the agreement could be that in the cases of both Kyriazakis \& Emmans (1995) and of Whittemore et al. (2002) the food fed after the changeover was not constraining food intake. The data from Whittemore et al. (2002) and Kyriazakis \& Emmans (1995) show that neither the $70 \% \mathrm{WB}$ nor the $48 \% \mathrm{WB}$ food was limiting at the time they were fed and that growth rates on both were comparable to that achieved on the control food. If the food is not constraining then animals will be able to meet their DFI and hence the capacity to consume food bulk and whether or not there is a maximum capacity, are both irrelevant.

\section{Conclusions}

The model was designed to be able to predict changes in food intake over time during the period over which adaptation to the new food occurs. Qualitatively the predictions of the model are in close agreement with relevant observed data in at least some cases. We conclude that the underlying theoretical assumptions of the model are reasonable. The main failures of the model are (1) prediction of initial intake on being changed to foods of high WB content and (2) prediction of intake of a non-limiting food where compensatory intake and gain occur. It may be possible to adapt the model to overcome the first reason for failure by dealing explicitly with the time course of digestive efficiency following the change to a new food. To deal with the second reason for failure would need a sufficient understanding of the time course of compensatory growth. This is not currently available. 


\section{Acknowledgements}

The work was funded in part by Finnfeeds International Ltd, PIC Group, and ABN Ltd. The Scottish Agricultural College receives financial support from the Scottish Executive, Environment and Rural Affairs Department. We are grateful to Ian Wellock and Candido Pomar for their comments on an earlier version of the manuscript.

\section{References}

Agricultural Research Council (1981) The Nutrient Requirements of Pigs, Technical review by an ARC working party. Farnham Royal, UK: Commonwealth Agricultural Bureaux.

Black JL, Campbell RG, Williams IH, James KJ \& Davies GT (1986) Simulation of energy and amino acid utilisation in the pig. Research and Development in Agriculture 3, 121-145.

Cole DJA, Hardy B \& Lewis D (1972) Nutrient density of pigs diets. In Pig Production, pp. 61-70 [DJA Cole, editor]. London: Butterworths.

Ehle FR, Jeraci JL, Robertson JB \& Van Soest PJ (1982) The influence of dietary fiber on the digestibility, rate of passage and gastrointestinal fermentation in pigs. Journal of Animal Science 55, 1071-1081.

Emmans GC (1987) Growth, body composition and feed intake. World Poultry Science Association Journal 43, 208-227.

Emmans GC (1988) Genetic components of potential and actual growth. In Animal Breeding Opportunities, British Society of Animal Production, Occasional Publication no. 12. pp. 153-181 [RB Land, G Bullfield and WG Hill, editors].

Emmans GC (1994) Effective energy: a concept of energy utilisation applied across species. British Journal of Nutrition 71, 801-821.

Emmans GC (1997) A method to predict the food intake of domestic animals from birth to maturity as a function of time. Journal of Theoretical Biology 186, 189-199.

Emmans GC \& Fisher C (1986) Problems in nutritional theory. In Nutrient Requirements of Poultry and Nutritional Research, pp. 9-39 [C Fisher and KN Boorman, editors]. London: Butterworths.

Emmans GC \& Kyriazakis I (1995) A general method for predicting the weight of water in the empty body of pigs. Animal Science 61, 103-108.

Emmans GC \& Kyriazakis I (1997) Models of pig growth: problems and proposed solutions. Livestock Production Science 51, 119-129.

Emmans GC \& Kyriazakis I (1999) Growth and body composition. In A Quantitative Biology of the Pig, pp. 181-197 [I Kyriazakis, editor]. Wallingford, Oxon: CABI Publishing.

Emmans GC \& Kyriazakis I (2001) Consequences of genetic change in farm animals on food intake and feeding behaviour. Proceedings of the Nutrition Society 60, 115-125.

Ferguson NS, Gous RM \& Emmans GC (1994) Preferred components for the construction of a new simulation model of growth, feed intake and nutrient requirements of growing pigs. South African Journal of Animal Science 24, 10-17.

Forbes JM (2001) Consequences of feeding for future feeding. Comparative Biochemistry and Physiology 128A, 463-470.

Giles LR, Lorschy ML, Bray HJ \& Black JL (1998) Predicting feed intake in growing pigs. In Progress in Pig Science, pp. 209-228 [J Wiseman, MA Varley and JP Chadwick, editors]. Nottingham: Nottingham University Press.

Knap PW (2000) Time trends of Gompertz growth parameters in 'meat-type' pigs. Animal Science 70, 39-49.
Kotarbinska M (1969) An Investigation into the Transformation of Energy in Growing Pigs. Wydewinctiva Walsne, nr. 238. Wroclaw: Institut Zootechniki, (in Polish).

Kyriazakis I \& Emmans GC (1992a) The effects of varying protein and energy intakes on the growth and body composition of pigs 1 . The effects of energy intake at constant, high protein intake. British Journal of Nutrition 68, 615-625.

Kyriazakis I \& Emmans GC (1992b) The effects of varying protein and energy intakes on the growth and body composition of pigs 2. The effects of varying both energy and protein intake. British Journal of Nutrition 68, 603-613.

Kyriazakis I \& Emmans GC (1995) The voluntary feed intake of pigs given feeds based on wheatbran, dried citrus pulp and grass meal in relation to measurements of feed bulk. British Journal of Nutrition 73, 191-207.

Kyriazakis I \& Emmans GC (1999) Voluntary feed intake and diet selection. In A Quantitative Biology of the Pig, pp. 229-248 [I Kyriazakis, editor]. Wallingford, Oxon: CABI Publishing.

Kyriazakis I, Stamataris C, Emmans GC \& Whittemore CT (1991) The effects of food protein content on the performance of pigs previously given foods with low or moderate protein contents. Animal Production 52, 165-173.

Low AG (1985) Role of dietary fibre in pigs diets. In Recent Advances in Animal Nutrition, pp. 87-112 [W Haresign and DJA Cole, editors]. London: Butterworths.

National Research Council (1987) Predicting Feed Intake of Food-Producing Animals. Washington, DC: National Academy Press.

Noblet J \& Bach Knudsen KE (1997) Comparative digestibility of wheat, maize and sugar beet pulp non-starch polysaccharides in adult sows and growing pigs. In Proceedings of the 7th International Symposium on Digestive Physiology in Pigs, EAAP publication no. 88. pp. 571-574 [JP Laplace, C Fevrier and A Barbeau, editors].

Noblet J, Shi XS \& Dubois S (1993) Metabolic utilisation of dietary energy and nutrients for maintenance energy requirements in sows - basis for a net energy system. British Journal of Nutrition 70, 407-419.

Nyman M \& Nils-Georg A (1982) Fermentation of dietary fibre components in the rat intestinal tract. British Journal of Nutrition 47, 357-366.

Owen JB, Ridgeman WJ \& Wyllie D (1971) The effect of food restriction on subsequent voluntary intake of pigs. Animal Production 13, 537-546.

Poppi DP, Gill M \& France J (1994) Integration of theories of feed intake regulation in growing ruminants. Journal of Theoretical Biology 167, 129-145.

Provenza FD \& Balph DF (1987) Diet learning by domestic ruminants - theory, evidence and practical implications. Applied Animal Behavioural Science 18, 211-232.

Robinson DW (1964) The plane of nutrition and compensatory growth in pigs. Animal Production 6, 227-236.

Schinkel AP (1999) Describing the pig. In A Quantitative Biology of the Pig, pp. 9-38 [I Kyriazakis, editor]. Wallingford, Oxon: CABI Publishing.

Selvandran RR (1984) The plant cell wall as a source of dietary fibre: chemistry and structure. American Journal of Clinical Nutrition 39, 320-337.

Stamataris C, Hillyer GM, Whittemore CT, Emmans GC, Taylor AG \& Philips P (1985) Performance and body composition of young pigs following a period of growth retardation by food restriction. Animal Production 40, 536.

Tsaras LN, Kyriazakis I \& Emmans GC (1998) The prediction of voluntary feed intake of pigs on poor quality feeds. Animal Science 66, 713-723. 
Varel (1987) Activity of fiber-degrading microorganisms in the pig large intestine. Journal of Animal Science 65, 488-496.

Whittemore CT, Green DM \& Knap PW (2001a) Technical review of the energy and protein requirements of growing pigs: food intake. Animal Science 73, 3-17.

Whittemore CT, Tullis JB \& Emmans GC (1988) Protein growth in pigs. Animal Production 46, 437-445.

Whittemore EC, Emmans GC, Tolkamp BJ \& Kyriazakis I (2001c) Tests of two theories of food intake using growing pigs 2 . The effect of a period of reduced growth rate on the subsequent intake of foods of differing bulk content. Animal Science 72, 361-373.

Whittemore EC, Kyriazakis I, Emmans GC Tolkamp BJ (2001b)

Tests of two theories of food intake using growing pigs 1 . The effect of ambient temperature on the intake of foods of differing bulk content. Animal Science 72, 351-360.

Whittemore EC, Kyriazakis I, Tolkamp BJ \& Emmans GC (2002) The short-term feeding behaviour of growing pigs fed foods differing in bulk content. Physiology and Behavior 76, $131-141$. 